\title{
Morphometric profile of tendocalcaneus of South Africans of European ancestry using a cadaveric approach
}

\author{
S. Latiff'10, M.A. Bidmos²(1), O.I. Olateju'1(1) \\ 'School of Anatomical Sciences, Faculty of Health Sciences, University of the Witwatersrand, Johannesburg, South Africa \\ 2College of Medicine, QU Health, Qatar University, Doha, Qatar
}

[Received: 29 January 2020; Accepted: 13 February 2020]

\begin{abstract}
Background: Tendocalcaneus is a strong tendon that is vital for bipedalism in humans. Despite its tremendous strength, the tendocalcaneus is prone to damage and degeneration causing mobility problems and pain. Morphometric dimension of the tendocalcaneus is of benefit to the surgical repair and reconstruction of the damaged tendon. Cadaveric approach provides a realistic method for determining tendocalcaneus morphometry and as at present only two cadaveric studies on Indian population is available. Thus this study presents data on tendocalcaneus morphometry in South Africans of European ancestry using a cadaveric approach. Materials and methods: A total of 66 lower limbs (32 left and 34 right legs) sourced from 49 male and female cadavers were used. After careful dissection of the posterior aspect of leg, the medial and lateral length, distal width, distal circumference and proximal width of the tendocalcaneus were measured.

Results: The data showed a high degree of reproducibility indicating that the measurements obtained using cadaveric approach were precise and accurate. There was no difference in measurements between the sides. Measurements in the males were generally higher than in the females. Strong associations were observed between the paired measurements of the medial and lateral tendon length and between the distal width and distal circumference.

Conclusions: The data obtained will be useful in predicting tendocalcaneus size during the surgical reconstruction of the tendocalcaneus. (Folia Morphol 2021; 80, 1: 196-203)
\end{abstract}

Key words: cadavers, European ancestry, Achilles morphometry, tendon, South African

\section{INTRODUCTION}

Tendocalcaneus (TC) is a strong, whitish and poorly vascularized tendon in the posterior compartment of the leg where it serves as the insertion, via a conjoint tendon, for the gastrocnemius and soleus and sometimes the plantaris $[9,10,33]$. The conjoint tendon inserts to the supero-posterior aspect of the calcaneal tuberosity [31]. With this arrangement, the calf muscles are able to plantarflex the foot at the ankle joint thus make the
TC vital for bipedalism in humans [31]. In addition, the TC transmits force from the muscle to the foot bones during walking and as such it endures a significant strain and stress which may explain the reason for its high mechanical strength and flexibility [40, 43, 44]. Mechanical strength is also reinforced by the tightly packed bundles of collagen fibres in the tendon $[13,25]$.

The TC is one of the most commonly injured tendons in humans $[14,22,29,32,45]$. The most com- 
mon site of rupture is $2-6 \mathrm{~cm}$ from its insertion point due to the small cross sectional area (CSA) at this region, its large eccentric loads and reduced vascularity $[9,38]$. TC rupture is due to a sudden or aggressive dorsiflexion of a plantar-flexed foot which then causes the sudden displacement of the weight-bearing foot with the knee in extension [14]. Most TC injuries are related to sport $[14,15,21]$ or could be as a result of overuse or age-related stiffness that reduces the ability of an individual to withstand stress [39, 48]. Similarly, spontaneous TC rupture has been reported in dialysis and renal transplant patients [42]. Although the exact cause remains controversial however calcium phosphate build-up and the use of steroid treatment in renal failure often cause weakening of tendons $[5,28,42]$. Interestingly, there is reduced injury incidence in older individuals unless the tendon is subjected to sudden rapid contractions which can then cause the tendon to tear $[14,27,43]$. Age-related reduction in collagen content also makes the tendon more prone to repetitive tears due to a decrease in the mechanical strength of the tendon [35]. Whereas in athletes or physically active individuals, the constant use of the tendon predisposes them to higher risk of injury than in less active individuals $[37,39]$ because the mechanical properties are dependent on the extent of mechanical strain put on each of the limbs i.e. a case of loading versus strength of the tendon [2].

The propensity of TC to damage and the subsequent surgical repair or management makes it crucial to understand its morphometry in different population groups. Only two studies are available on the morphometry of TC using a cadaveric approach and both studies utilized cadavers of Indian population [19, 41]. Data that closely match the TC dimensions in the living in different population groups will be of benefit to surgical repair and management of tendinopathy. The present study assessed the TC morphometry of South Africans of European ancestry using a cadaveric approach. Cadavers were utilised as they provide a realistic measurement and a better morphological description in a three-dimensional [19, 34] compared to a highly-subjective two-dimensional ultrasound scans [47]. According to Thoirs and Childs [47], image acquisition using ultrasound is identified as the major contributor to measurement errors of the TC. These errors are due to variations in equipment, positioning of the subject and stabilisation of the lower limb, non-standardized transducer pressure, transducer orientation and equipment settings $[46,47]$.
Table 1. Demographics of cadavers and distribution of lower limbs

\begin{tabular}{lcccccc}
\hline Sex & \multicolumn{2}{c}{ Age } & & \multicolumn{3}{c}{ Side } \\
\cline { 2 - 3 } \cline { 5 - 7 } & Mean & SD & & Left & Right & Total \\
\hline Female & 76.9 & 11.2 & & 17 & 18 & 35 \\
Male & 74.6 & 11.3 & & 15 & 16 & 31 \\
\cline { 5 - 7 } & & & 32 & 34 & 66 \\
\hline
\end{tabular}

SD - standard deviation

\section{MATERIALS AND METHODS}

\section{Sample population}

A total of 34 right ( 18 female and 16 male) and 32 left (17 female and 15 male) lower limbs from cadavers of South Africans of European ancestry (Table 1) were used which were housed in the School of Anatomical Sciences at the University of the Witwatersrand, Johannesburg, South Africa for teaching purposes. Approval was granted (Ethics Number: W-CJ-140604-1) by the Human Research Ethics Committee (Medical) of the same university. Therefore the study was conducted in accordance with the ethical standards. From the cadavers available for this study, 17 left and 17 right limbs (i.e. both limbs) were sourced from the same cadavers and the rest were from 32 cadavers. The mean age of the female cadavers was 76.9 years (range: 53-94 years) and that of the male cadavers was 74.6 years (range: $52-93$ years) (Table 1). Cadavers with any physical scars or deformity on the lower limb were excluded from the study.

\section{Anatomical dissection}

With the body in the prone position and the lower limb in full extension, a longitudinal incision was made on the posterior surface of each lower limb extending from the popliteal fossa to the inferior aspect of the calcaneus bone. The skin was carefully reflected to reveal the underlying structures. The subcutaneous fascia and fat were also removed. The crural fascia was then cut open to expose the muscles in the posterior compartment of the leg. At the popliteal fossa, a $2.5 \mathrm{~cm}$ transverse incision was made in the medial and the lateral direction (perpendicular to the longitudinal incision) to allow for adequate space to examine the deep structures without compromising the use of the cadavers for teaching purposes. Similarly, at the heel, about $5 \mathrm{~cm}$ long incisions were made on the medial and lateral sides of the foot (also perpendicular to the longitudinal incision). 


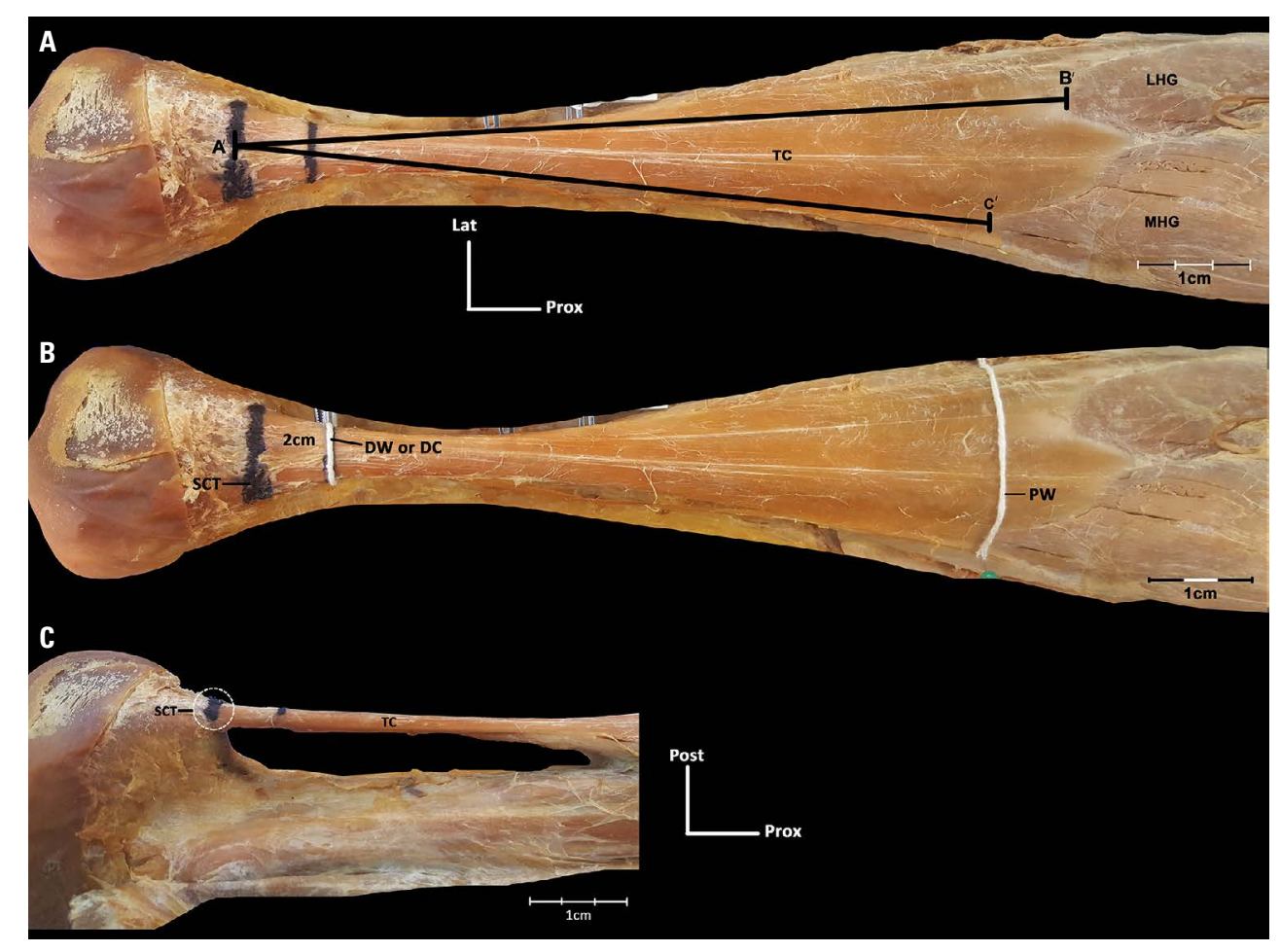

Figure 1. Photographs showing the tendocalcaneus (TC) on the posterior compartment of the left leg and the description of the measured parameters; $\mathbf{A}$. The dissection revealing the level of the superior aspect of calcaneal tuberosity (SCT) and measurement of the medial length of tendon ( $\mathrm{LOT}_{\mathrm{M}^{\prime}}$; point $\mathrm{A}^{\prime}$ to $\mathrm{B}^{\prime}$ ) and lateral length of tendon ( $\mathrm{LOT}_{\mathrm{L}^{\prime}}$; point $\mathrm{A}^{\prime}$ to $\mathrm{C}^{\prime}$ ); $\mathbf{B}$. The levels at which measurement for the distal width (DW) and distal circumference $(D C ; 2 \mathrm{~cm}$ from the level of $\mathrm{SCT}$ ) and then the proximal width (PW; lowest level of musculotendinous junction of the gastrocnemius) were performed; C. The lateral view of the SCT and a portion of the length of TC; LHG — lateral head of gastrocnemius; MHG — medial head of gastrocnemius; Lat — lateral; Prox — proximal; Post — posterior.

\section{Measurements}

With the knee in full extension and the foot in a dorsiflexed position (approximately $90^{\circ}$ ), modified measurements (Fig. 1) previously described by Kumar et al. [19] were taken on each limb. Soft tissue within the area of the calcaneus and deep to the TC was cleared until the superior aspect of the calcaneus was visible (Fig. 1C). Similar to Liem et al. [23], Ebeling et al. [11] and Kumar et al. [19], the superior aspect of the calcaneal tuberosity was used as the reference point from which all measurements were taken in order to reduce variability in the measurements. Also for repeatability, the distal width and circumference (Fig. 1B) were measured $2 \mathrm{~cm}$ from the reference point $[11,23]$ while the proximal width was determined at the lowest level of the musculotendinous junction of the gastrocnemius [3, 35, 36]. Due to ease of access, visibility and without cutting the TC that may compromise measuring its actual length, the medial and lateral lengths of the tendon (Fig. 1A) were considered to be the actual length of the TC which is a slight modification to the measurements by Kumar et al. [19]. This modification was used because there is a significant variation to the extent or level at which the gastrocnemius and the soleus muscles contribute to the formation of the TC due to the non-constant orientation of the tendon fibrils $[7,9,10]$.

The measurements used in the present study are summarized below:

- medial length of the tendon $\left(\mathrm{LOT}_{\mathrm{M}}\right)$ - distance from the superior aspect of the calcaneal tuberosity to the lowest point of the musculotendinous junction of the medial head of the gastrocnemius muscle (Metre rule);

- lateral length of the tendon ( $\mathrm{LOT}_{\mathrm{L}}$ ) - distance from the superior aspect of the calcaneal tuberosity to the lowest point of the musculotendinous junction of the lateral head of the gastrocnemius muscle (Metre rule);

- distal width (DW) - measurement taken at a level $2 \mathrm{~cm}$ above the superior aspect of the calcaneal tuberosity (Vernier calliper);

- proximal (PW) width - measurement taken at the lowest point on the musculotendinous junction of the gastrocnemius muscle (Thread and metre rule); 
- distal circumference (DC) - measurement taken at a level $2 \mathrm{~cm}$ above the superior aspect of the calcaneal tuberosity (around the distal width) (Thread and metre rule). The superior aspect of the calcaneal tuberosity was used as a reference point for the DW and DC (Fig. 1B).

\section{Statistical analyses}

An inter-observer reliability test (Lin's concordance test) was used to determine the level of precision and accuracy between the measurements [20, 24]. This test was performed to determine the degree of agreement between test and retest measurements. After establishing that the measuring technique is adequate, data were collected separately for male and female groups. Descriptive statistics including means and standard deviation was obtained for each measurement. A Student's t-test was used to determine side and sex differences for each measurement. In addition, a Pearson's correlation coefficient was used to assess the strength of the association between the different dimensions of the TC. All statistical analyses were performed using SPSS software (version 22.0; IBM, US). Statistical difference of $5 \%$ was regarded significant for all the statistical analyses.

\section{RESULTS}

\section{Test of reliability of measurements}

The Lin's concordance correlation coefficient $\left(P_{c}\right)$ for all measurements is shown in Table 2. The $P_{c}$ ranged between 0.971 for DW and 0.995 for LOT $_{L}$, which indicates a high degree of reproducibility. The measurement technique is therefore precise and accurate based on the result of the $P_{c}$. The measurement error from subsequent data collected and analysed for the current study is considered minimal and acceptable.

\section{Assessment of side difference}

A comparison of mean measurements from both sides were made separately for male and female samples from cadavers whose both lower limbs were dissected. Table 3 shows that there is no statistically significant differences between the two sides indicating a lack of side dominance.

\section{Descriptive statistics}

The mean and standard deviation for each measurement of the left and right TC are presented in Table 4. The LOT $_{M^{\prime}}$ LOT $_{L^{\prime}}$ DC and DW (right leg) of the
Table 2. Lin's concordance correlation of reproducibility

\begin{tabular}{lc}
\hline Measurements & Pc \\
\hline LOT $_{M}$ & 0.993 \\
LOT $_{L}$ & 0.995 \\
DW & 0.971 \\
DC & 0.990 \\
PW & 0.990 \\
\hline
\end{tabular}

$\mathrm{LOT}_{\mathrm{M}}$ - medial length of tendon; $\mathrm{LOT}_{\mathrm{L}}$ — lateral length of tendon; DW - distal width; $\mathrm{DC}$ - distal circumference; $\mathrm{PW}$ - proximal width

TC displayed sexual dimorphism but not the PW and the DW (left leg).

\section{Correlation analyses}

The associations for the different TC dimensions were separated to give clear details about the relationship between any paired measurements with respect to sex and side. Using the Pearson's correlation coefficients [1], strong associations were observed between the paired measurements of LOT $_{L}$ and LOT $_{M}$ $(R \geq 0.8)$ for both sexes and sides. Association between $\mathrm{DC}$ and DW $(\mathrm{R} \geq 0.7)$ was similarly strong except for the male left leg. In addition, association between DW and PW showed a negative strong association $(R=-0.7)$ in the male left leg. Other paired measurements displayed moderate associations $(R=0.4-0.6)$. The association between measurements of the right and left TC for both sexes showing only the strong and moderate associations is presented in Table 5.

\section{DISCUSSION}

Ultrasound is the most preferred method for diagnosing TC rupture and which is also commonly utilised in determining the TC morphometry $[3,8,11$, $17,35,36]$. There is usually a high variability in the TC dimension when measurement is obtained from images acquired using ultrasound. This variability is due to the non-uniformities of equipment, different resolutions of equipment and image acquisition parameters [46, 47]. For example, Pang and Ying [35] observed that the measurement outcome for CSA did not correspond with the TC thickness in their study on TC morphometry using an ultrasound. They concluded that this was so because the measured CSA was more accurate than the TC thickness. Thus the approach used (i.e. ultrasound) was implicated as the source of errors or variability [35]. This therefore means that there is a need to present data on TC morphometry that is more precise and accurate. The results of the present study showed a high degree 
Table 3. Comparison between mean measurements of left and right tendocalcaneus

\begin{tabular}{|c|c|c|c|c|c|c|c|c|c|c|c|c|c|c|}
\hline & \multicolumn{7}{|c|}{ Female } & \multicolumn{7}{|c|}{ Male } \\
\hline & \multirow[b]{2}{*}{$\mathbf{N}$} & \multicolumn{2}{|c|}{ Left } & \multicolumn{2}{|c|}{ Right } & \multirow[b]{2}{*}{$t$} & \multirow[b]{2}{*}{ p } & \multirow[b]{2}{*}{$\mathbf{N}$} & \multicolumn{2}{|c|}{ Left } & \multicolumn{2}{|c|}{ Right } & \multirow[b]{2}{*}{$t$} & \multirow[b]{2}{*}{ p } \\
\hline & & Mean & SD & Mean & SD & & & & Mean & SD & Mean & SD & & \\
\hline $\mathrm{LOT}_{\mathrm{M}}$ & 10 & 173.0 & 22.4 & 162.4 & 15.9 & 1.22 & 0.24 & 7 & 193.4 & 22.9 & 191.4 & 26.0 & 0.15 & 0.88 \\
\hline $\mathrm{LOT}_{\mathrm{L}}$ & 10 & 194.4 & 23.1 & 186.3 & 10.3 & 1.01 & 0.33 & 7 & 228.5 & 28.8 & 220.1 & 21.2 & 0.62 & 0.55 \\
\hline DW & 10 & 12.9 & 3.8 & 13.2 & 3.6 & 0.18 & 0.86 & 7 & 14.9 & 2.2 & 15.6 & 1.7 & 0.67 & 0.52 \\
\hline$D C$ & 10 & 40.3 & 8.0 & 40.4 & 8.1 & 0.03 & 0.98 & 7 & 45.3 & 4.2 & 43.7 & 4.3 & 0.71 & 0.49 \\
\hline PW & 10 & 73.2 & 9.5 & 71.3 & 6.3 & 0.53 & 0.61 & 7 & 66.1 & 5.9 & 73.6 & 11.6 & 1.52 & 0.15 \\
\hline
\end{tabular}

$\mathrm{LOT}_{\mathrm{M}}$ - medial length of tendon; $\mathrm{LOT}_{\mathrm{L}}$ - lateral length of tendon; DW - distal width; DC — distal circumference; PW — proximal width; $\mathrm{SD}$ - standard deviation

Table 4. Descriptive statistics of measurements of the tendocalcaneus

\begin{tabular}{|c|c|c|c|c|c|c|c|c|}
\hline & \multicolumn{3}{|c|}{ Female } & \multicolumn{3}{|c|}{ Male } & \multirow[b]{2}{*}{$t$} & \multirow[b]{2}{*}{ p } \\
\hline & $\mathbf{N}$ & Mean & SD & $\mathbf{N}$ & Mean & SD & & \\
\hline \multicolumn{9}{|l|}{ Left } \\
\hline $\mathrm{LOT}_{\mathrm{M}}$ & 17 & 178.4 & 25.3 & 15 & 202.5 & 20.7 & 3.04 & 0.005 \\
\hline $\mathrm{LOT}_{\mathrm{L}}$ & 17 & 197.0 & 19.4 & 15 & 227.5 & 24.3 & 4.04 & 0.000 \\
\hline DW & 17 & 13.9 & 3.3 & 15 & 15.8 & 2.1 & 1.98 & $0.057^{*}$ \\
\hline$D C$ & 17 & 41.2 & 6.7 & 15 & 46.1 & 4.5 & 2.42 & 0.022 \\
\hline PW & 17 & 72.8 & 9.4 & 15 & 71.6 & 13.7 & 0.61 & $0.766^{*}$ \\
\hline \multicolumn{9}{|l|}{ Right } \\
\hline $\mathrm{LOT}_{\mathrm{M}}$ & 18 & 173.4 & 21.4 & 16 & 195.1 & 22.5 & 2.88 & 0.007 \\
\hline $\mathrm{LOT}_{\mathrm{L}}$ & 18 & 194.7 & 16.4 & 16 & 219.4 & 18.3 & 4.17 & 0.000 \\
\hline DW & 18 & 13.1 & 2.8 & 16 & 15.3 & 1.9 & 2.63 & 0.013 \\
\hline$D C$ & 18 & 38.4 & 6.5 & 16 & 43.2 & 3.7 & 2.62 & 0.013 \\
\hline PW & 18 & 71.2 & 7.5 & 16 & 75.4 & 13.6 & 1.12 & $0.273^{*}$ \\
\hline
\end{tabular}

${ }^{*}$ No significant difference at $\mathrm{p} \leq 0.05 ; \mathrm{LOT}_{\mathrm{M}}$ - medial length of tendon; $\mathrm{LOT}$ — lateral length of tendon; $\mathrm{DW}$ — distal width; DC — distal circumference; PW - proximal width; $\mathrm{SD}$ standard deviation

Table 5. Correlation coefficient between measurements of the left and right tendocalcaneus

\begin{tabular}{|c|c|c|c|c|c|c|c|c|c|c|}
\hline & \multicolumn{5}{|c|}{ Female } & \multicolumn{5}{|c|}{ Male } \\
\hline & $\mathrm{LOT}_{\mathrm{M}}$ & $\mathrm{LOT}_{\mathrm{L}}$ & DW & DC & PW & $\mathrm{LOT}_{\mathrm{M}}$ & $\mathrm{LOT}_{\mathrm{L}}$ & DW & DC & PW \\
\hline \multicolumn{11}{|l|}{ Left } \\
\hline \multicolumn{11}{|l|}{$\mathrm{LOT}_{\mathrm{M}}$} \\
\hline $\mathrm{LOT}_{\mathrm{L}}$ & 0.9 & & & & & 0.8 & & & & \\
\hline DW & 0.4 & & & & & & & & & \\
\hline $\mathrm{DC}$ & & & 0.9 & & & & & 0.6 & & \\
\hline PW & & & 0.5 & 0.4 & & & 0.4 & -0.7 & & \\
\hline \multicolumn{11}{|l|}{ Right } \\
\hline \multicolumn{11}{|l|}{$\mathrm{LOT}_{\mathrm{M}}$} \\
\hline $\mathrm{LOT}_{\mathrm{L}}$ & 0.8 & & & & & 0.8 & & & & \\
\hline DW & 0.5 & 0.5 & & & & 0.4 & & & & \\
\hline$D C$ & 0.6 & 0.6 & 0.9 & & & & & 0.7 & & \\
\hline PW & & & & & & & & 0.6 & 0.4 & \\
\hline
\end{tabular}

$\mathrm{LOT}_{\mathrm{M}}$ - medial length of tendon; $\mathrm{LOT}$ - lateral length of tendon; $\mathrm{DW}-$ distal width; $\mathrm{DC}$ - distal circumference; $\mathrm{PW}-$ proximal width 
of reproducibility indicating that the measurements obtained were precise and accurate. Cadaveric approach seems to be a more idealistic approach as it provides a three-dimensional view of the structure from which measurements of different parameters and direct observations can be conducted. Only few data on the TC morphometry using cadaveric approach is available (e.g. Kumar et al. [19]); however, its benefits have been utilised in similar studies such as patella-patellar ligament morphometry [34].

The result of the present study is consistent with that obtained for other studies in that the TC dimensions were not significantly different between the sides [8]. The base-line morphometric profile of the TC is very useful as it has been shown that the tendon properties of both TC are asymmetrical [2]. Thus a morphometric distinction between a pathological and a non-pathological tendon is of paramount importance in the surgical repair of the TC and post-surgery mobility recovery. In addition, the differences in the TC morphometry between sides may not be entirely pathological but may be as a result of sidedness [2]. Leg dominance with respect to TC is particularly interesting in that some studies $[2,12,35]$ reported the left leg as the dominant leg despite the fact that a significant number of people are right-sided [26, 35]. In the study by Pang and Ying [35], the participants were asked to elect a limb to kick a ball. A significant number elected the right limb but their elected limb was considered non-dominant. This makes sense in that the left ankle in right-sided individuals endures significant tension while acting as push off during certain activities e.g. ball kicking. This also accounts for the high prevalence of left TC injuries owing to the fact that many individuals are right-sided [26, 35].

Several factors, e.g. subjects' physical activities, sex and age, have been suggested to be contributing factors to the differences in the TC morphometry $[2,34,35]$. Differences in foot types also have a direct relationship with the TC morphometry [30] as a thin TC is often associated with a flat-arched foot type due to the reduced effectiveness of the transfer of force from the heel to the forefoot during the propulsion phase of walking $[18,49]$. Likewise, a thin TC is also more prone to rupture and it is more vulnerable to developing tendinopathy than a thicker TC [16]. It is thus logical to observe morphometric variations in measurements taken within any population group (e.g. athlete vs. non-athlete) and the variation could be more significant between different population groups. Despite the differences in approaches used (e.g. ultrasound or cadaveric) for TC morphometry, the mean values for the distal width in the present study is within close range with other ultrasound studies $[4,8,17,36]$. However it differs from Kumar et al. [19] and Singhal et al. [41] that measured the tendon near their insertions unlike the present the study that took measurements at the region where the TC is most prone to injury. The mean values also fall within the range that were reported for white, non-white or black population groups $[8,36]$. This consistency could be attributed to the superficial position of this section of the TC (i.e. distal part) that makes it easy to measure when using any of the two approaches.

Tendon degeneration is common in old age due to a reduction in the collagen fibrils but results in an increase in tendon fibrils [35]. These two factors contribute to the differences in TC morphometric. The reduction in collagen in-turn lowers the mechanical strength of tendon making aged individuals to be more prone to repetitive tears $[6,16]$. As tendon constantly remodels in order to repair the repetitive tears, the healing tendon hypertrophies which could thus introduce more variability in the TC dimension across any population group. Most cadavers in our facility are aged and it is thus a limitation for the present cadaveric study.

In the present study, strong associations were found between the medial and lateral lengths of the TC and between the distal width and distal circumference of the TC of both legs while moderate to weak associations were reported for other paired measurements in the legs for both sexes. Kumar et al. [19] similarly reported weak to moderate associations in the TC dimensions in the male cadavers. In the latter study, weak associations were reported for paired measurements between the tendon length and the tendon circumferences (proximal and distal) similar to the findings of the present study for the male cadavers. There was also a weak association between the tendon length and the rest of the measurements [19]. Moderate associations were reported between proximal and distal widths as well as between distal width and distal circumference [19] which are similar to the results of the present study. The significant similarities between the present findings and the report by Kumar et al. [19] further indicates the adequacy of a cadaveric method for determining the TC morphometry. Based on the strong associations, it seems that the TC length, distal width and distal circumference could be dependable factors for predicting the normal 
size of the TC. This will be of help to surgeons during the surgical repairs of the TC.

\section{CONCLUSIONS}

The presented morphometric profiles of the TC using a cadaveric approach are considered highly accurate suggesting that the measurements obtained may closely match that in the living of similar age. Although cadaveric approach is faced with numerous limitations (e.g. age range owing to cadaveric collection, sample size, population group etc.), it still offers a realistic approach for morphometric measurements. A more comprehensive morphometric data of the TC that takes into account the body weight, stature, physical activities and pathologies etc. still need to be conducted as this will be helpful during the surgical repair of the tendon. Future studies should also incorporate the measurement of CSA of the TC across different population groups using histological approach. This may shed more light into the associations between the tendon length, the TC distal width and distal circumference where most TC injuries often occur.

\section{Acknowledgements}

This study would not be possible without the aid of those who donated their bodies toward the advancement of medical science. We are grateful to the School of Anatomical Sciences of the University of the Witwatersrand for giving us access to the Human Collections. The National Research Foundation of South Africa provided Student Financial aid to S. Latiff (first author).

\section{REFERENCES}

1. Akoglu H. User's guide to correlation coefficients. Turk J Emerg Med. 2018; 18(3): 91-93, doi: 10.1016/j. tjem.2018.08.001, indexed in Pubmed: 30191186.

2. Bohm S, Mersmann F, Marzilger R, et al. Asymmetry of Achilles tendon mechanical and morphological properties between both legs. Scand J Med Sci Sports. 2015; 25(1): e124-e132, doi: 10.1111/sms.12242, indexed in Pubmed: 24798645.

3. Brouwer EF, Myhrvold SB, Benth JŠ, et al. Ultrasound measurements of Achilles tendon length using skin markings are more reliable than extended-field-of-view imaging. Knee Surg Sports Traumatol Arthrosc. 2018; 26(7): 2088-2094, doi: 10.1007/s00167-017-4815-0, indexed in Pubmed: 29185003.

4. Canbolat M, Özbağ D, Özdemir Z, et al. Effects of physical characteristics, exercise and smoking on morphometry of human Achilles tendon: an ultrasound study. Anatomy. 2016; 9(3): 128-134, doi: 10.2399/ana.15.022.

5. Cohen IK, Diegelmann RF, Johnson ML. Effect of corticosteroids on collagen synthesis. Surgery. 1977; 82(1): 15-20, indexed in Pubmed: 877852.
6. Cook JL, Khan KM, Kiss ZS, et al. Asymptomatic hypoechoic regions on patellar tendon ultrasound: A 4-year clinical and ultrasound followup of 46 tendons. Scand J Med Sci Sports. 2001; 11(6): 321-327, doi: 10.1034/j.16000838.2001.110602.x, indexed in Pubmed: 11782263.

7. Cummins EJ, Anson BJ. The structure of the calcaneal tendon (of Achilles) in relation to orthopedic surgery, with additional observations on the plantaris muscle. Surg Gynecol Obstet. 1946; 83: 107-116, indexed in Pubmed: 20988044.

8. Mello R, Marchiori E, Santos A, et al. Avaliação morfométrica do tendão de Aquiles por ultra-sonografia. Radiol Bras. 2006; 39(3): 161-165, doi: 10.1590/s010039842006000300003.

9. Del Buono A, Chan O, Maffulli N. Achilles tendon: functional anatomy and novel emerging models of imaging classification. Int Orthop. 2013; 37(4): 715-721, doi: 10.1007/ s00264-012-1743-y, indexed in Pubmed: 23254856.

10. Doral MN, Alam M, Bozkurt M, et al. Functional anatomy of the Achilles tendon. Knee Surg Sports Traumatol Arthrosc. 2010; 18(5): 638-643, doi: 10.1007/s00167-0101083-7, indexed in Pubmed: 20182867.

11. Ebeling T, Farin P, Pyörälä K. Ultrasonography in the detection of Achilles tendon xanthomata in heterozygous familial hypercholesterolemia. Atherosclerosis. 1992; 97(2-3): 217-228, doi: 10.1016/0021-9150(92)90134-3, indexed in Pubmed: 1466665.

12. Egwu A. Normal thickness of the tendo calcaneus (TCT) in an adult nigerian population: an imaging based normographic study. Br J Med Med Res. 2014; 4(10): 2100-2111, doi: 10.9734/bjmmr/2014/5678.

13. Eriksen HA, Pajala A, Leppilahti J, et al. Increased content of type III collagen at the rupture site of human Achilles tendon. J Orthop Res. 2002; 20(6): 1352-1357, doi: 10.1016/ S0736-0266(02)00064-5, indexed in Pubmed: 12472252.

14. Hess GW. Achilles tendon rupture: a review of etiology, population, anatomy, risk factors, and injury prevention. Foot Ankle Spec. 2010; 3(1): 29-32, doi: 10.1177/1938640009355191, indexed in Pubmed: 20400437.

15. Järvinen TAH, Kannus $P$, Maffulli N, et al. Achilles tendon disorders: etiology and epidemiology. Foot Ankle Clin. 2005; 10(2): 255-266, doi: 10.1016/j.fcl.2005.01.013, indexed in Pubmed: 15922917.

16. Jhingan S, Perry M, O'Driscoll G, et al. Thicker Achilles tendons are a risk factor to develop Achilles tendinopathy in elite professional soccer players. Muscles Ligaments Tendons J. 2011; 1(2): 51-56, indexed in Pubmed: 23738247.

17. Kallinen $M$, Suominen $H$. Ultrasonographic measurements of the Achilles tendon in elderly athletes and sedentary men. Acta Radiol. 1994; 35(6): 560-563, indexed in Pubmed: 7946678.

18. Koivunen-Niemelä T, Parkkola K. Anatomy of the Achilles tendon (tendo calcaneus) with respect to tendon thickness measurements. Surg Radiol Anat. 1995; 17(3): 263-268, doi: 10.1007/BF01795061, indexed in Pubmed: 7502192.

19. Kumar N, Aithal AP, Nayak SB, et al. Morphometric evaluation of human tendocalcaneus: a cadaveric study of south indian male population. Muscles Ligaments Tendons J. 2017; 7(1): 62-68, doi: 10.11138/mltj/2017.7.1.062, indexed in Pubmed: 28717613.

20. Landis JR, Koch GG. The measurement of observer agreement for categorical data. Biometrics. 1977; 33(1): 159-174, indexed in Pubmed: 843571. 
21. Lantto I, Heikkinen J, Flinkkilä T, et al. Epidemiology of Achilles tendon ruptures: increasing incidence over a 33-year period. Scand J Med Sci Sports. 2015; 25(1): e133-e138, doi: 10.1111/sms.12253, indexed in Pubmed: 24862178.

22. Leppilahti J, Puranen J, Orava S. Incidence of Achilles tendon rupture. Acta Orthop Scand. 1996; 67(3): 277-279, doi: 10.3109/17453679608994688, indexed in Pubmed: 8686468.

23. Liem MS, Leuven JA, Bloem JL, et al. Magnetic resonance imaging of Achilles tendon xanthomas in familial hypercholesterolemia. Skeletal Radiol. 1992; 21(7): 453-457, doi: 10.1007/BF00190990, indexed in Pubmed: 1439898.

24. Lin LK. A concordance correlation coefficient to evaluate reproducibility. Biometrics. 1989; 45(1): 255, doi: 10.2307/2532051.

25. Maffulli N, Ewen SW, Waterston SW, et al. Tenocytes from ruptured and tendinopathic achilles tendons produce greater quantities of type III collagen than tenocytes from normal achilles tendons. An in vitro model of human tendon healing. Am J Sports Med. 2000; 28(4): 499-505, doi: 10.1177/03635465000280040901, indexed in Pubmed: 10921640.

26. Maffulli N, Waterston SW, Squair J, et al. Changing incidence of Achilles tendon rupture in Scotland: a 15-year study. Clin J Sport Med. 1999; 9(3): 157-160, doi: 10.1097/00042752-199907000-00007, indexed in Pubmed: 10512344.

27. Magnusson SP, Beyer $\mathrm{N}$, Abrahamsen $\mathrm{H}$, et al. Increased cross-sectional area and reduced tensile stress of the Achilles tendon in elderly compared with young women. J Gerontol A Biol Sci Med Sci. 2003; 58(2): 123-127, doi: 10.1093/gerona/58.2.b123, indexed in Pubmed: 12586849.

28. Mirahmadi KS, Coburn JW, Bluestone R. Calcific periarthritis and hemodialysis. JAMA. 1973; 223(5): 548-549, indexed in Pubmed: 4739139.

29. Möller A, Astron M, Westlin N. Increasing incidence of Achilles tendon rupture. Acta Orthop Scand. 1996; 67(5): 479-481, doi: 10.3109/17453679608996672, indexed in Pubmed: 8948254.

30. Murley GS, Tan JM, Edwards RM, et al. Foot posture is associated with morphometry of the peroneus longus muscle, tibialis anterior tendon, and Achilles tendon. Scand J Med Sci Sports. 2014; 24(3): 535-541, doi: 10.1111/sms.12025, indexed in Pubmed: 23301865.

31. Nickisch F. Anatomy of the Achilles Tendon. Achilles Tendon. 2008: 2-16, doi: 10.1007/978-0-387-79205-7 1.

32. Nillius SA, Nilsson BE, Westlin NE. The incidence of Achilles tendon rupture. Acta Orthop Scand. 1976; 47(1): 118-121, doi: 10.3109/17453677608998983, indexed in Pubmed: 1266586.

33. O'Brien M. The anatomy of the Achilles tendon. Foot Ankle Clin. 2005; 10(2): 225-238, doi: 10.1016/j. fcl.2005.01.011, indexed in Pubmed: 15922915.

34. Olateju O, Philander I, Bidmos M. Morphometric analysis of the patella and patellar ligament of South Africans of European ancestry. South African J Sci. 2013; 109(9/10): 1-6, doi: 10.1590/sajs.2013/20130069.

35. Pang B, Ying M. Sonographic measurement of Achilles tendons in asymptomatic subjects. J Ultrasound Med. 2006; 25(10): 1291-1296, doi: 10.7863/ jum.2006.25.10.1291.
36. Patel NN, Labib SA. The Achilles tendon in healthy subjects: an anthropometric and ultrasound mapping study. J Foot Ankle Surg. 2018; 57(2): 285-288, doi: 10.1053/j. jfas.2017.10.005, indexed in Pubmed: 29275904.

37. Rosager $S$, Aagaard P, Dyhre-Poulsen P, et al. Load-displacement properties of the human triceps surae aponeurosis and tendon in runners and non-runners. Scand J Med Sci Sports. 2002; 12(2): 90-98, doi: 10.1034/j.16000838.2002.120205.x, indexed in Pubmed: 12121426.

38. Saltzman CL, Tearse DS. Achilles tendon injuries. J Am Acad Orthop Surg. 1998; 6(5): 316-325, doi: 10.5435/00124635-199809000-00007, indexed in Pubmed: 9753759.

39. Schepsis AA, Jones $H$, Haas AL. Achilles tendon disorders in athletes. Am J Sports Med. 2002; 30(2): 287-305, doi: 10.1177/03635465020300022501, indexed in Pubmed: 11912103.

40. Sharma P, Maffulli N. Biology of tendon injury: healing, modeling and remodeling. J Musculoskelet Neuronal Interact. 2006; 6(2): 181-190, indexed in Pubmed: 16849830.

41. Singhal M, Parmar N, Singhal D, et al. Morphometric analysis of tendoachilles tendon with its clinical implications. Int J Anat Res. 2019; 7(2.2): 6550-6555, doi: 10.16965/ ijar.2019.165.

42. Spencer JD. Spontaneous rupture of tendons in dialysis and renal transplant patients. Injury. 1988; 19(2): 86-88, doi: 10.1016/0020-1383(88)90079-4, indexed in Pubmed: 3058609.

43. Stenroth L, Peltonen J, Cronin NJ, et al. Age-related differences in Achilles tendon properties and triceps surae muscle architecture in vivo. J Appl Physiol (1985). 2012; 113(10): 1537-1544, doi: 10.1152/japplphysiol.00782.2012, indexed in Pubmed: 23042907.

44. Strocchi R, De Pasquale V, Guizzardi S, et al. Human Achilles tendon: morphological and morphometric variations as a function of age. Foot Ankle. 1991; 12(2): 100-104, doi: 10.1177/107110079101200207, indexed in Pubmed: 1773989.

45. Suchak AA, Bostick $G$, Reid $D$, et al. The incidence of Achilles tendon ruptures in Edmonton, Canada. Foot Ankle Int. 2005; 26(11): 932-936, doi: 10.1177/107110070502601106, indexed in Pubmed: 16309606.

46. Syha R, Grau S, Nieß AM, et al. Computer-based quantification of the Achilles tendon thickness in sequential B-mode ultrasound images: a study of feasibility and reliability. Arch Orthop Trauma Surg. 2014; 134(10): 1443-1449, doi: 10.1007/s00402-014-2043-3, indexed in Pubmed: 25052771.

47. Thoirs KA, Childs J. Are ultrasound measurements of achilles tendon size reliable? A systematic review of rater reliability. Ultrasound Med Biol. 2018; 44(12): 2476-2491, doi: 10.1016/j.ultrasmedbio.2018.07.011, indexed in Pubmed: 30154035.

48. van Dijk CN, van Sterkenburg MN, Wiegerinck JI, et al. Terminology for Achilles tendon related disorders. Knee Surg Sports Traumatol Arthrosc. 2011; 19(5): 835-841, doi: 10.1007/ s00167-010-1374-z, indexed in Pubmed: 21222102.

49. Van Ginckel A, Thijs $Y$, Hesar NG, et al. Intrinsic gait-related risk factors for Achilles tendinopathy in novice runners: a prospective study. Gait Posture. 2009; 29(3): 387-391, doi: 10.1016/j. gaitpost.2008.10.058, indexed in Pubmed: 19042130. 